\title{
Clinical Image on Sigmoid Volvulus (Ileo-Sigmoidal Knoting) in Mearg General Hospital West Tigray, Ethiopia
}

\section{Solomon Gebre*}

Emergency Surgical Department, Mearg General Hospital, Dansha, West Tigray, Ethiopia

"Corresponding author: Solomon Gebre, Emergency Surgical Department, Mearg General Hospital, Dansha, West Tigray, Ethiopia, Tel: 251911366834; E-mail: solomongebre300@gmail.com

Received date: July 09, 2017; Accepted date: July 10, 2017; Published date: July 15, 2017

Copyright: () 2017 Gebre S, et al. This is an open-access article distributed under the terms of the Creative Commons Attribution License, which permits unrestricted use, distribution, and reproduction in any medium, provided the original author and source are credited.

\section{Introduction}

This is a 28 years Para four mothers on her third post-partum period presented with sever persistent abdominal pain, vomiting, fever, fast breathing and failure to pass faces and flatus of three days duration. Investigation $\mathrm{Hct}=18 \% \mathrm{Bg}$ and $\mathrm{Rh}=\mathrm{O}$ +ve $\mathrm{PAF}$ shows multiple air fluid level with distended colon. On physical examination $\mathrm{Bp}=80 / 40 \mathrm{mmHg} \mathrm{T}=38.8 \mathrm{PR}=131 \mathrm{bpm} \mathrm{RR}=32 \mathrm{bpm}$ pale conjunctiva, grossly distended abdomen, sever direct and rebound tenderness, involuntary abdominal guarding and empty rectum on PR. The Intraoperative finding were ileosigmoidal knotting (ileum were wrapped around the sigmoid) with gangrenous ileum and sigmoid. Untying the knot, resection of gangrenous ileum and sigmoid colon, ileo-transfers end to side anastomosis and end sigmoid colostomy was done (Figure 1-3).

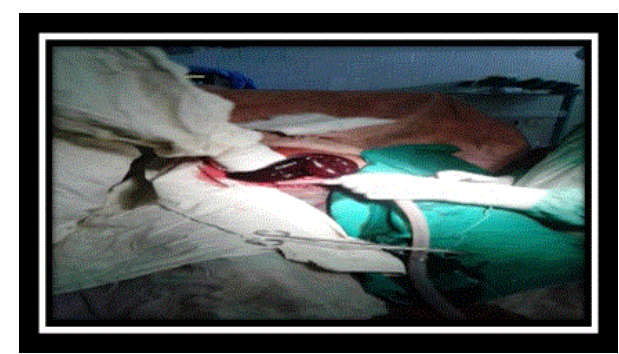

Figure 1: Gangrenous small bowel (Terminal Ileum).

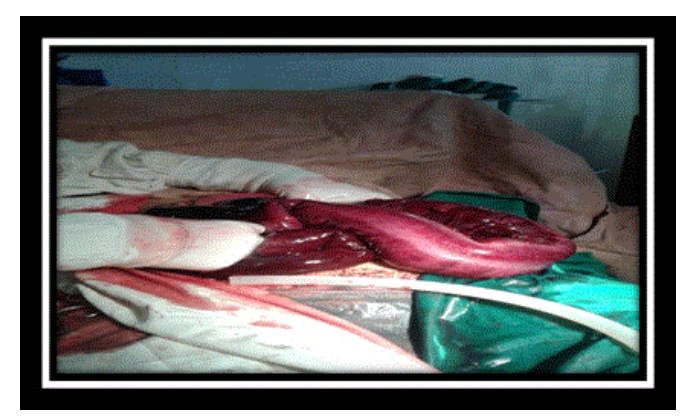

Figure 2: Gangrenous small (Terminal Ileum) and large bowel (Sigmoid). 